Jan Claassen

Fabio S. Taccone

Peter Horn

Martin Holtkamp

Nino Stocchetti

Mauro Oddo

\title{
Recommendations on the use of EEG monitoring in critically ill patients: consensus statement from the neurointensive care section of the ESICM
}

Received: 8 April 2013

Accepted: 14 April 2013

Published online: 8 May 2013

(c) Springer-Verlag Berlin Heidelberg and

ESICM 2013

\section{J. Claassen \\ Department of Neurology, Division of Critical Care Neurology, Columbia University Medical Center, New York, NY, USA}

\section{F. S. Taccone}

Department of Intensive Care Medicine, Erasme Hospital, Université Libre de Bruxelles, Brussels, Belgium

\section{P. Horn}

Department of Neurosurgery,

Horst-Schmidt-Klinik, Wiesbaden, Germany

\section{Holtkamp}

Department of Neurology, Charité

University Medicine, Berlin, Germany

\section{N. Stocchetti}

Department of Anesthesia and Critical Care, Neuroscience ICU, Fondazione IRCCS Cà Granda-Ospedale Policlinico, University of Milan, Milan, Italy
M. Oddo (®)

Department of Intensive Care Medicine, Faculty of Biology of Medicine, CHUVLausanne University Hospital, 1011

Lausanne, Switzerland

e-mail: mauro.oddo@chuv.ch

Tel.: +41-79-5561246

Fax: +41-21-3143045

\begin{abstract}
Objectives: Recommendations for EEG monitoring in the ICU are lacking. The Neurointensive Care Section of the ESICM assembled a multidisciplinary group to establish consensus recommendations on the use of EEG in the ICU. Methods: A systematic review was performed and 42 studies were included. Data were extracted using the PICO approach, including: (a) population, i.e. ICU patients with at least one of the following: traumatic brain injury, subarachnoid hemorrhage, intracerebral hemorrhage, stroke, coma after cardiac arrest, septic and metabolic encephalopathy, encephalitis, and status epilepticus; (b) intervention, i.e. EEG monitoring of at least 30 min duration; (c) control, i.e. intermittent vs. continuous EEG, as no studies compared patients with a specific clinical condition, with and without EEG monitoring; (d) outcome endpoints, i.e. seizure detection, ischemia
\end{abstract}

detection, and prognostication. After selection, evidence was classified and recommendations developed using the GRADE system. Recommendations: The panel recommends EEG in generalized convulsive status epilepticus and to rule out nonconvulsive seizures in brain-injured patients and in comatose ICU patients without primary brain injury who have unexplained and persistent altered consciousness. We suggest EEG to detect ischemia in comatose patients with subarachnoid hemorrhage and to improve prognostication of coma after cardiac arrest. We recommend continuous over intermittent EEG for refractory status epilepticus and suggest it for patients with status epilepticus and suspected ongoing seizures and for comatose patients with unexplained and persistent altered consciousness. Conclusions: EEG monitoring is an important diagnostic tool for specific indications. Further data are necessary to understand its potential for ischemia assessment and coma prognostication.

Keywords EEG - Intensive care · Seizures - Cerebral ischemia . Prognosis $\cdot$ Recommendations 


\section{Introduction}

Acute brain dysfunction is a leading cause of admission to the ICU, either due to structural diseases, for example traumatic brain injury (TBI), intracranial hemorrhage, cerebral ischemia and encephalitis, or to functional disorders, for example septic encephalopathy. Electroencephalography (EEG) provides information about brain electrical activity, even when brain function is depressed and cannot be explored otherwise, as in comatose patients. EEG is essential to detect electrical seizures and to document their duration and response to therapy. It can disclose alterations associated with the development of delayed cerebral ischemia (DCI) and improve coma prognostication. It is useful to monitor barbiturate coma for refractory intracranial hypertension [1] and is mandatory in several countries for the diagnosis of brain death [2].

Evidence, however, is sparse, and recommendations for EEG monitoring in the ICU are not well defined. The Neurointensive Care (NIC) Section of the ESICM assembled a multidisciplinary panel to establish a consensus statement on the use of EEG monitoring in adult ICU populations. The aim was to provide better guidance for EEG monitoring and to improve implementation of EEG in ICU practice. Two indications were excluded from this review: EEG for brain death diagnosis, since it is regulated by local legislation in many countries, and for barbiturate coma, since it has been reviewed in authoritative guidelines [1].

\section{Methods}

Authors and study selection

In 2010, the NIC section of the ESICM decided to develop evidence-based consensus recommendation on the indications for EEG monitoring for ICU patients. Authors were proposed during an official NIC section meeting and included neurointensivists (N.S., J.C.), medical/surgical intensivists (F.S.T., M.O.), anesthesiologists (N.S.), neurologists (J.C.), neurosurgeons (P.H.) and epileptologists (M.H.) who would review the existing literature and provide a consensus manuscript. This systematic review was reported following the PRISMA criteria [3].

\section{Eligibility criteria}

Studies were considered eligible based on the PICO approach, which includes: (a) Population, i.e. ICU patients with at least one of the following: TBI, subarachnoid hemorrhage (SAH), intracerebral hemorrhage (ICH), acute ischemic stroke (AIS), coma after cardiac arrest (CA), sepsis/ metabolic encephalopathy, encephalitis, and status epilepticus (SE).

(b) Intervention, i.e. EEG monitoring of $>30 \mathrm{~min}$ duration.

(c) Controls, i.e. intermittent vs. continuous EEG, as no studies compared patient population with a specific clinical condition with and without EEG.

(d) Outcome endpoints, i.e. seizure detection, ischemia detection, prognostication.

\section{Search strategy}

Using the PubMed database, we conducted a systematic review from 1966 up to August 2012. The search strategy included the terms "EEG" or "electroencephalogram" or "electroencephalography", used with one of the following: "intensive care" or "critical care" or "ischemia" or "prognosis" or "outcome" or "traumatic brain injury" or "subarachnoid hemorrhage" or "intracerebral hemorrhage" or "stroke" or "cardiac arrest" or "sepsis" or "metabolic encephalopathy" or "encephalitis" or "meningitis" or "status epilepticus". Additional references for relevant studies were also searched from review articles. We restricted the language of the articles to English. No unpublished data or congress abstracts were considered.

\section{Study selection}

Two authors (M.O. and F.S.T.) independently reviewed citations, abstracts and full-text articles to select eligible studies. We excluded: (a) review articles, (b) case reports, (c) experimental studies, (d) studies in pediatric ICU populations, (e) studies that were not conducted on ICU patients. Data were abstracted (F.S.T.) according to the PICO system. No attempt was made to re-analyze the data; accuracy of data extraction was controlled thereafter (M.O.). No additional process to obtain data from investigators was attempted. Considering the lack of randomized or case-control studies, no meta-analysis of extracted data was performed nor did we assess risk of bias or consistency, or perform subgroup analyses.

\section{Grading of evidence}

The quality of evidence was judged based on the grades of recommendation, assessment, development and evaluation (GRADE) system, which assesses the quality of evidence for each of the selected outcomes from the 
available studies, considering the benefit/risk balance and the costs related to the study intervention $[4,5]$. This system classifies quality of evidence as high (grade A), moderate (grade B), low (grade C), or very low (grade D) $[6,7]$. Thereafter, recommendations are classified as strong (grade 1) or weak (grade 2). One advantage of the GRADE system is that a strong recommendation can be made despite moderate/low evidence. Accordingly, the authors made strong recommendations when they were confident that the desirable effects of adherence to a recommendation would outweigh the undesirable effects. A strong recommendation reflects the possibility that following the given recommendation about EEG will result in more beneficial effects (detection and therapy of seizures, reduced injury associated with ongoing seizures, improved outcome, less burden on staff and patients, cost savings) than harm to ICU patients (inaccurate predictive value, useless antiepileptic drugs (AED), difficult EEG implementation). A weak recommendation reflects the opinion that the benefit/risk balance could be in favor of this recommendation, but the members of the task force were not confident because of limited evidence. Three authors (M.O., F.S.T., J.C.) proposed initial recommendations and asked for approval from the other participants. In case of disagreement, changes to recommendations were proposed and discussed to obtain a unanimous vote. It is important to recognize that strong recommendations do not necessarily represent standards of care.

\section{Results}

A total of 42 studies were selected (Fig. 1). All were retrospective or prospective observational single-center studies. No controlled trial-either nonrandomized or randomized-was identified (Table 1). Strong recommendations for EEG use, when given in the absence of high-quality evidence, are justified by the potential harm of unrecognized seizures and the low risk of the procedure; however, costs may be considerable and have to be weighed against the benefit. A summary of GRADE recommendations for the indications for EEG monitoring in the ICU is given in Table 2.

Patient populations

\section{EEG in patients with generalized convulsive SE}

Seizure detection Generalized convulsive SE (GCSE) is a clinical diagnosis that does not require EEG. However, nonconvulsive seizures $(\mathrm{NCSz})$ and nonconvulsive SE (NCSE) are frequent (48\% and $14 \%$, respectively) after GCSE [8] and differentiating ongoing seizure activity from postictal or medication-induced encephalopathy can be challenging. As clinical symptoms are often missing, EEG is necessary to diagnose ongoing NCSz [9, 10]. EEG, especially continuous EEG (cEEG), is urgently required in patients not waking up after cessation of clinical seizures to rule out NCSz [8, 11]. Guidelines for
Fig. 1 Flow-chart representing the methodology for the systematic review, according to the PRISMA criteria

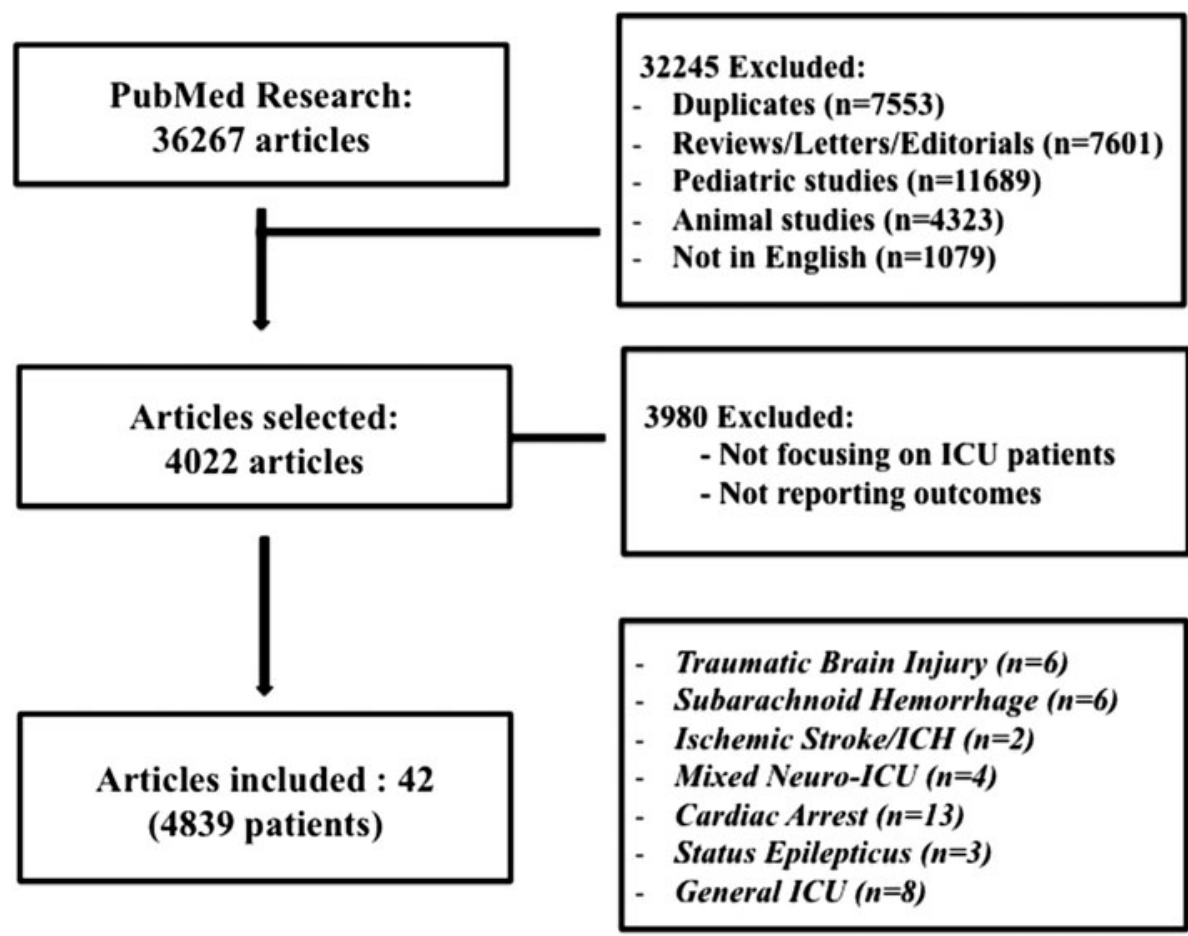




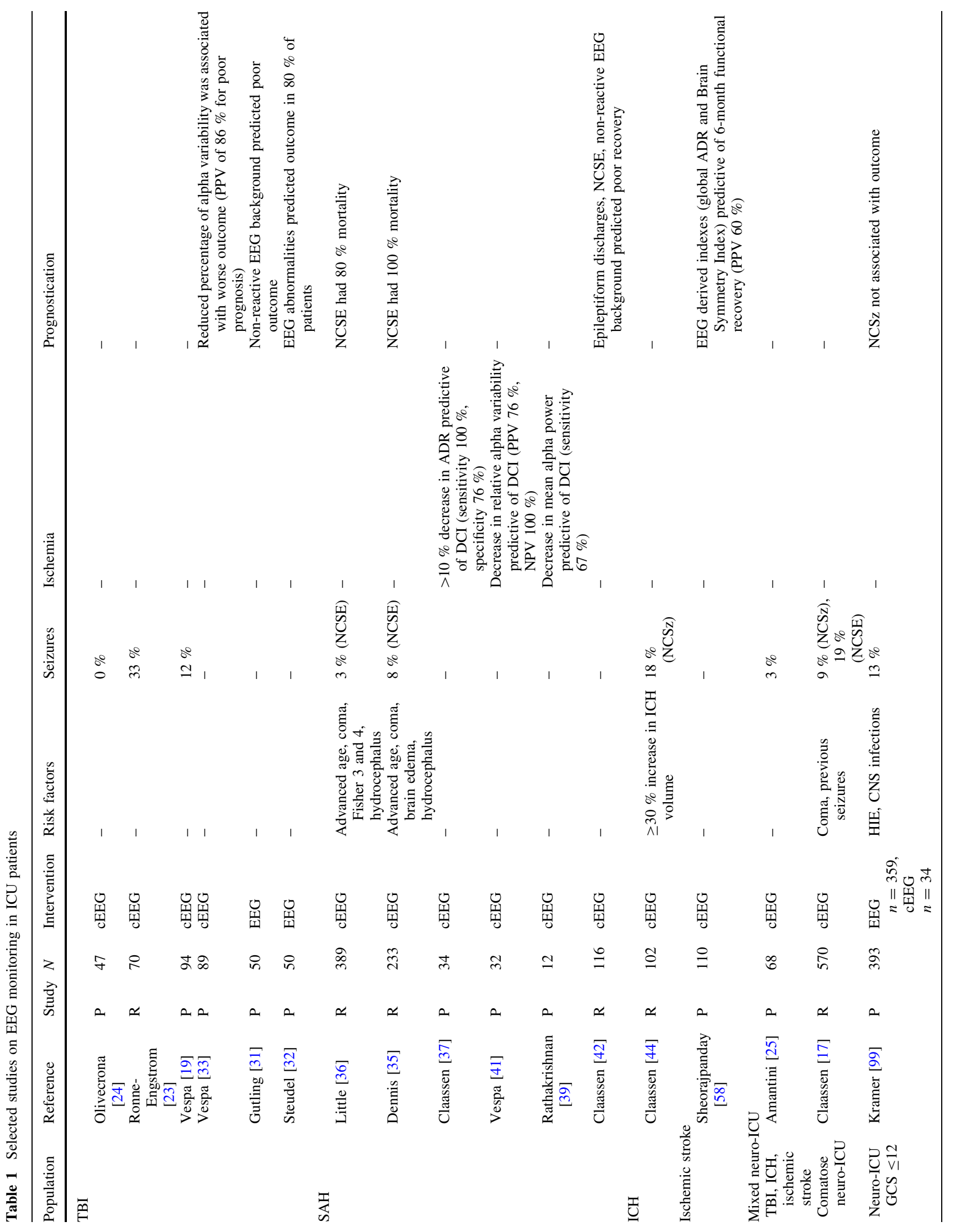




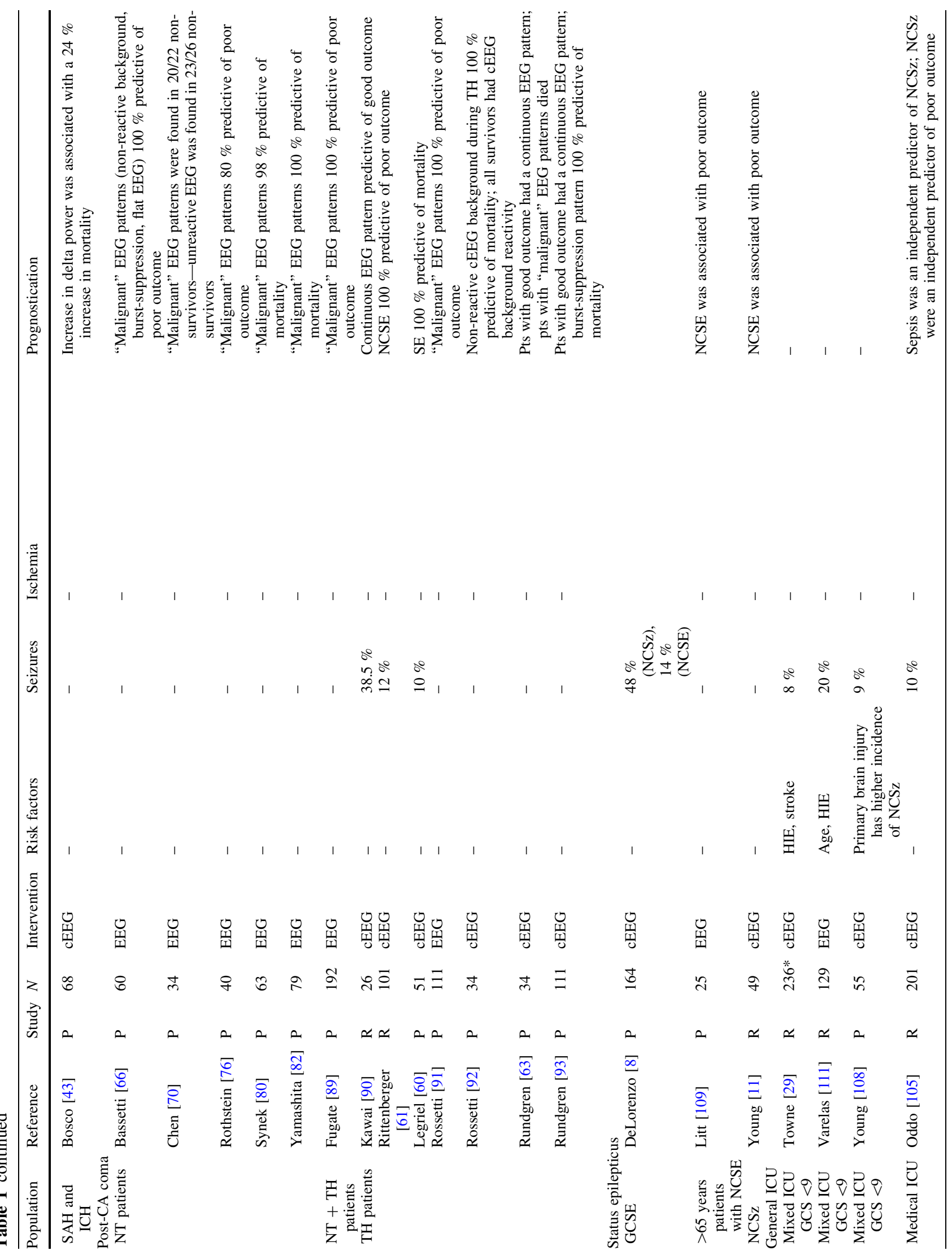




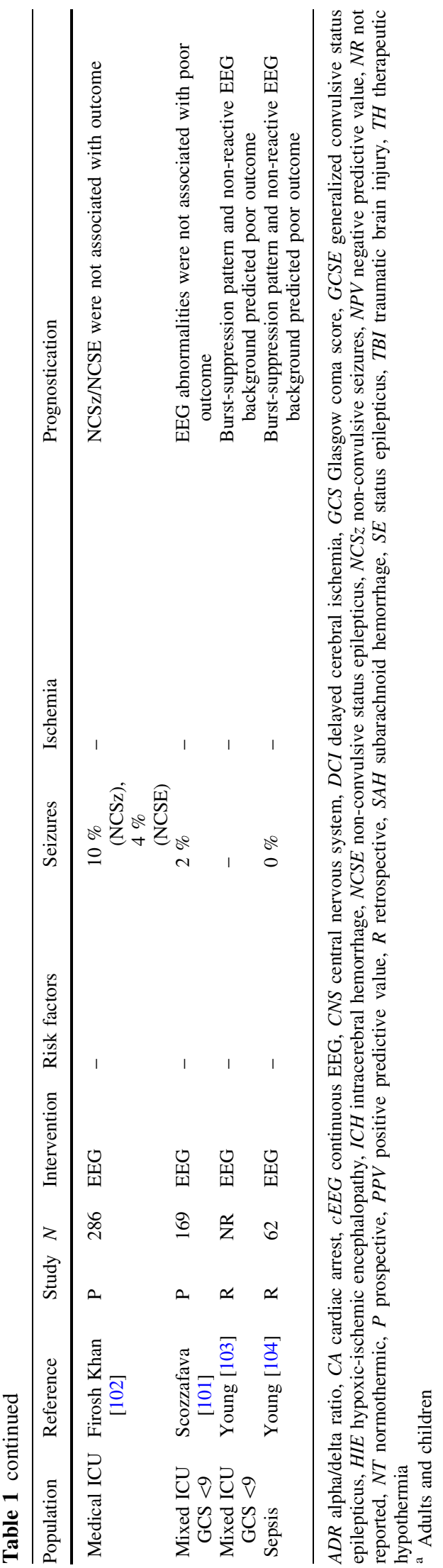

the management of SE in the ICU have recently been published [6].

\section{Recommendations for patients with convulsive $S E$}

1. We recommend urgent EEG in patients with SE that do not return to functional baseline within $60 \mathrm{~min}$ after administration of seizure medication (strong recommendation, low quality of evidence - grade 1C).

\section{EEG in patients with refractory $S E$}

SE resistant to initial therapy, also known as refractory SE (RSE), is almost exclusively nonconvulsive and requires initiation of intravenous AED [12-14]. CEEG is required to guide therapy for RSE, aiming to stop ongoing electrographic seizures. One study showed that although RSE initially responded to intravenous therapy, many patients subsequently developed NCSz, detectable only with cEEG [15]. There is controversy as to the minimum duration of monitoring [16-19] (see section "Technological issues"). Video-cEEG monitoring helps with the interpretation of complex electrographic abnormalities, but its efficacy over standard EEG has not been demonstrated yet [20].

\section{Recommendations for patients with refractory $S E$}

1. We recommend urgent (within $60 \mathrm{~min}$ ) EEG in patients with RSE (strong recommendation, low quality of evidence-grade 1C).

\section{EEG in patients with TBI}

Seizure detection Patients suffering from TBI are at risk of NCSz [21, 22]. Risk factors for NCSz are depressed skull fracture, penetrating injury and large cortical contusion/hematomas [22]. Observational studies in patients with TBI monitored by EEG have shown a variable prevalence of NCSz. Vespa et al. $(n=90$ patients, duration of cEEG 7 days) found a $22 \%$ prevalence of seizures, of which $52 \%$ were NCSz, despite AED prophylaxis [19]. Ronne-Engstrom and Winkler studied 70 patients (duration of cEEG $58 \mathrm{~h}$, no AED prophylaxis) and found a $33 \%$ prevalence of seizures (starting on average $74 \mathrm{~h}$ after TBI), the majority of which were NCSz [23]. The frequency of NCSz depends on the amount of sedatives used. Two recent studies, in which patients were given high sedative doses with intrinsic antiseizure activity, showed no [24] or a very low (3\%) [25] rate of NCSz. NCSz are associated with intracranial pressure elevations [26], increased cerebral metabolic distress [26] and long-term hippocampal atrophy [27]. 
Table 2 GRADE recommendations for the indications for EEG in the ICU

\begin{tabular}{|c|c|c|c|c|c|}
\hline \multicolumn{3}{|c|}{ GRADE recommendations } & \multicolumn{2}{|l|}{ Patient description } & \multirow[t]{2}{*}{ Objective } \\
\hline Direction & Strength & $\begin{array}{l}\text { Level of } \\
\text { evidence }\end{array}$ & Underlying etiology & Scenario & \\
\hline Pro & $\begin{array}{l}\text { Strong } \\
\text { (1) }\end{array}$ & $\begin{array}{l}\text { Low quality } \\
\text { (C) }\end{array}$ & $\begin{array}{l}\text { Generalized convulsive status } \\
\text { epilepticus }\end{array}$ & $\begin{array}{l}\text { No return to functional baseline } \\
\text { after initial antiepileptic therapy }\end{array}$ & $\begin{array}{l}\text { Detect nonconvulsive } \\
\text { seizures }\end{array}$ \\
\hline Pro & $\begin{array}{l}\text { Strong } \\
\text { (1) }\end{array}$ & $\begin{array}{l}\text { Low quality } \\
\text { (C) }\end{array}$ & Refractory status epilepticus & $\begin{array}{l}\text { Concern for ongoing seizure } \\
\text { activity }\end{array}$ & $\begin{array}{l}\text { Detect nonconvulsive } \\
\text { seizures }\end{array}$ \\
\hline Pro & $\begin{array}{l}\text { Strong } \\
\text { (1) }\end{array}$ & $\begin{array}{l}\text { Low quality } \\
\text { (C) }\end{array}$ & Traumatic brain injury & $\begin{array}{l}\text { Unexplained alteration in } \\
\text { consciousness }^{\mathrm{a}}\end{array}$ & $\begin{array}{l}\text { Detect nonconvulsive } \\
\text { seizures }\end{array}$ \\
\hline Pro & $\begin{array}{l}\text { Strong } \\
\text { (1) }\end{array}$ & $\begin{array}{l}\text { Low quality } \\
\text { (C) }\end{array}$ & Subarachnoid hemorrhage & $\begin{array}{l}\text { Unexplained alteration in } \\
\text { consciousness }^{\mathrm{a}}\end{array}$ & $\begin{array}{l}\text { Detect nonconvulsive } \\
\text { seizures }\end{array}$ \\
\hline Pro & $\begin{array}{l}\text { Strong } \\
\text { (1) }\end{array}$ & $\begin{array}{l}\text { Low quality } \\
\text { (C) }\end{array}$ & Intracerebral hemorrhage & $\begin{array}{l}\text { Unexplained alteration in } \\
\text { consciousness }^{\mathrm{a}}\end{array}$ & $\begin{array}{l}\text { Detect nonconvulsive } \\
\text { seizures }\end{array}$ \\
\hline Pro & $\begin{array}{l}\text { Strong } \\
\text { (1) }\end{array}$ & $\begin{array}{l}\text { Low quality } \\
\text { (C) }\end{array}$ & Cardiac arrest & Persistent coma & $\begin{array}{l}\text { Detect nonconvulsive } \\
\text { seizures }\end{array}$ \\
\hline Pro & $\begin{array}{l}\text { Strong } \\
\text { (1) }\end{array}$ & $\begin{array}{l}\text { Low quality } \\
\text { (C) }\end{array}$ & Encephalitis & $\begin{array}{l}\text { Unexplained alteration in } \\
\text { consciousness }^{\mathrm{a}}\end{array}$ & $\begin{array}{l}\text { Detect nonconvulsive } \\
\text { seizures }\end{array}$ \\
\hline Pro & $\begin{array}{l}\text { Strong } \\
\text { (1) }\end{array}$ & $\begin{array}{l}\text { Low quality } \\
\text { (B) }\end{array}$ & $\begin{array}{l}\text { Comatose patients without } \\
\text { primary brain injury }\end{array}$ & $\begin{array}{l}\text { Unexplained alteration in } \\
\text { consciousness }^{\mathrm{a}}\end{array}$ & $\begin{array}{l}\text { Detect nonconvulsive } \\
\text { seizures }\end{array}$ \\
\hline Pro & $\begin{array}{l}\text { Weak } \\
(2)\end{array}$ & $\begin{array}{l}\text { Low quality } \\
\text { (C) }\end{array}$ & Severe traumatic brain injury & $\begin{array}{l}\text { Concern for ongoing seizure activity } \\
\text { in high-risk patients (large cortical } \\
\text { hemorrhagic contusion/hematoma) }\end{array}$ & $\begin{array}{l}\text { Detect nonconvulsive } \\
\text { seizures }\end{array}$ \\
\hline Pro & $\begin{array}{l}\text { Weak } \\
\text { (2) }\end{array}$ & $\begin{array}{l}\text { Very low } \\
\text { quality (D) }\end{array}$ & Acute ischemic stroke & $\begin{array}{l}\text { Unexplained alteration in } \\
\text { consciousness }^{\mathrm{a}}\end{array}$ & $\begin{array}{l}\text { Detect nonconvulsive } \\
\text { seizures }\end{array}$ \\
\hline Pro & $\begin{array}{l}\text { Weak } \\
\text { (2) }\end{array}$ & $\begin{array}{l}\text { Low quality } \\
\text { (C) }\end{array}$ & Subarachnoid hemorrhage & $\begin{array}{l}\text { Patients in whom clinical } \\
\text { examination is unreliable }\end{array}$ & Detect ischemia \\
\hline Pro & $\begin{array}{l}\text { Weak } \\
(2)\end{array}$ & $\begin{array}{l}\text { Low quality } \\
\text { (C) }\end{array}$ & Cardiac arrest & Persistent coma & Prognostication \\
\hline Pro & $\begin{array}{l}\text { Weak } \\
(2)\end{array}$ & $\begin{array}{l}\text { Low quality } \\
\text { (C) }\end{array}$ & All comatose ICU patients & $\begin{array}{l}\text { Unexplained alteration in } \\
\text { consciousness }^{\mathrm{a}}\end{array}$ & Prognostication \\
\hline Pro & $\begin{array}{l}\text { Weak } \\
\text { (2) }\end{array}$ & $\begin{array}{l}\text { Very low } \\
\text { quality (D) }\end{array}$ & Encephalitis & $\begin{array}{l}\text { Unexplained alteration in } \\
\text { consciousness }^{\mathrm{a}}\end{array}$ & Prognostication \\
\hline
\end{tabular}

${ }^{a}$ Unexplained alteration in consciousness: reduced consciousness state that is not attributable to metabolic disorders (sodium, calcium, glucose, ammonium, urea), organ dysfunction (hypotension, hypoxemia, sepsis, hyperthermia) or structural brain lesions on imaging (cerebral CT scan) tests

Despite variable results and lack of multicenter studies, there is a strong rationale for EEG monitoring after TBI. This is reinforced by the fact that primary AED prophylaxis is frequently unreliable in preventing or suppressing NCSz [28].

Ischemia detection No study has shown a role for EEG in detecting ischemia after TBI.

Prognostication Towne et al. [29] and Vespa et al. [19] were unable to demonstrate a difference in mortality between TBI patients with or without EEG seizures. EEG reactivity to auditory or nociceptive stimuli predicted good outcome after TBI, whereas absent EEG reactivity resulted in a poor outcome $[30,31]$ with a higher predictive value than GCS and somatosensory evoked potentials. In another study, EEG performed daily during the first week after admission reliably predicted outcome in 40/50 patients; however, prognosis could not be assessed in patients with alpha pattern coma or in those receiving barbiturate therapy [32]. Reduced percentage of alpha variability also predicted outcome in TBI patients with GCS $\leq 8$ (positive predictive value $86 \%$ ) [33].

\section{Recommendations for patients with TBI}

1. We recommend EEG in all TBI patients with unexplained and persistent altered consciousness (strong recommendation, low quality of evidence-grade 1C).

2. We suggest EEG to rule out NCSz in patients with TBI and GCS $\leq 8$, particularly in those with large cortical contusion/hematoma, depressed skull fracture or penetrating injury (weak recommendation, low quality of evidence-grade $2 \mathrm{C}$ ).

\section{EEG in patients with $S A H$}

Seizure detection Acute seizures have been reported in between $3 \%$ and $26 \%$ of patients with comatose SAH [34-36]. Of those undergoing cEEG in the ICU, 3-19\% 
have NCSz and $13 \%$ have NCSE, which cannot be diagnosed without EEG. Risk factors for seizures include older age, poor clinical grade, large intraparenchymal hemorrhage, large amount of cisternal blood, DCI, and anterior circulation aneurysm. Seizures may be less likely in patients that have undergone coil embolization of the aneurysm [34].

Ischemia detection In SAH patients, changes in EEG trends on cEEG (performed on days 2-10) correlate with DCI [37-41]. A number of quantitative EEG (qEEG) parameters may be useful, including changes in total power, alpha/delta ratio (ADR), composite alpha index, and relative alpha variability. There is controversy over which parameter is best, but all fundamentally relate to fast to slow frequencies. QEEG can detect EEG changes associated with DCI $24-48 \mathrm{~h}$ prior to other diagnostic tools $[39,41]$. Reported sensitivity is variable but can be as high as $90 \%$ [37, 38], with $75 \%$ specificity [37], and $100 \%$ negative predictive value and $76 \%$ positive predictive value [41].

Prognostication Epileptiform discharges or NCSE and absent EEG background reactivity was associated with poor prognosis after SAH [42]. Despite this association, there are no unequivocal human data indicating that $\mathrm{NCSz}$ are causally linked to poor functional outcome or that treatment improves outcome [34, 35, 42]. Progressive deterioration on the basis of EEG (increased delta pattern) was associated with an increased risk of dying by almost $24 \%$ compared to patients whose condition did not worsen according to EEG [43].

\section{Recommendations for patients with SAH}

1. We recommend EEG to rule out $\mathrm{NCSz}$ in all SAH patients with unexplained and persistent altered consciousness (strong recommendation, low quality of evidence-grade 1C).

2. We suggest EEG to detect DCI in comatose SAH patients, in whom neurological examination is unreliable (weak recommendation, low quality of evidence-grade 2C).

\section{EEG in patients with ICH}

Seizure detection Seizures are seen in 3-17\% of ICH patients, occurring at 1 day (50-70 \%) up to 3 days from ICH. Most seizures diagnosed in the ICU are non-convulsive (NCSz 53-76 \%, NCSE $39 \%$ ) and can only be diagnosed by EEG [44-46]. Risk factors include cortical bleeding and arteriovenous malformations [44, 46].

Ischemia detection No study has provided data on ischemia detection in ICH patients.
Prognostication Seizures are associated with an increase in ICH volume and worsening midline shift [44, 46]. NCSZ worsen neurological status, but an independent association with outcome has not been demonstrated $[44,46]$.

\section{Recommendations for patients with ICH}

1. We recommend EEG to rule out $\mathrm{NCSz}$ in all $\mathrm{ICH}$ patients with unexplained and persistent altered consciousness (strong recommendation, low quality of evidence-grade 1C).

\section{EEG in patients with AIS}

Seizure detection One single-center study in which cEEG was performed in 177 patients with AIS showed a $7 \%$ incidence of seizures (more than $70 \% \mathrm{NCSz}$ ) in the acute $(<24 \mathrm{~h})$ phase [45]. Seizures are less frequent than in $\mathrm{ICH}, \mathrm{SAH}$ or TBI patients.

Ischemia detection A decrease in cerebral perfusion pressure (CPP) may be associated with a concomitant reduction in faster EEG activity on qEEG [47], while rapid improvements in background EEG activity have been observed upon CPP/CBF increase following mannitol therapy [48] or hemodilution [49].

Prognostication Following hemicraniectomy for spaceoccupying middle cerebral artery infarction, the presence of faster EEG activity was associated with good recovery in patients monitored with cEEG [50]. Three studies have demonstrated that the disappearance or further slowing of delta activity in the acute phase (within $24 \mathrm{~h}$ ) of AIS predicted a malignant course (cerebral edema) [51-53].

Preliminary studies showed a correlation between the neurological score in the acute stage of AIS and the degree of EEG abnormality [54], although this correlation was shown to be low by others [55]. CEEG improves outcome prognostication in AIS [56-59]: in particularly, the ADR and the so-called EEG brain symmetry index are significantly correlated with outcome at 6 months [5659].

\section{Recommendations for patients with AIS}

1. We suggest EEG to rule out NCSz in all AIS patients with unexplained and/or persistently altered consciousness (weak recommendation, very low quality of evidence-grade 2D).

2. We do not recommend EEG to detect cerebral ischemia and target CPP in AIS patients (weak recommendation against, very low quality of evidence-grade 2D). 
3. We do not recommend EEG to detect herniation in AIS patients (weak recommendation against, very low quality of evidence-grade 2D).

\section{EEG in patients with coma after CA}

Seizure detection Seizures occur in 10-30\% of patients with coma after CA [60-63]. EEG is required to detect seizures as most seizures after $\mathrm{CA}$ are nonconvulsive and to differentiate myoclonic SE from peripheral or subcortical myoclonus. When therapeutic hypothermia (TH) is applied, seizures can occur during $\mathrm{TH}$ and after rewarming $[60,61,63]$. "Early" seizures, occurring during TH under sedation, are an ominous sign [60-63]. "Late" seizures, occurring after TH and off sedation, carry a poor prognosis but may respond to therapy in certain cases [64]: EEG is indicated to titrate therapy [61, 64].

Ischemia detection No study has provided data on ischemia detection in comatose CA patients or used EEG to target blood pressure management.

Prognostication Previous to $\mathrm{TH}$, a number of studies showed that adding EEG-performed at $72 \mathrm{~h}$ from CAto standard neurological examination improved outcome prognostication after CA [65-84]. EEG findings associated with a poor prognosis included spontaneous burst suppression or generalized periodic discharges. Synek analyzed EEG background activity (continuous vs. discontinuous pattern) and EEG background reactivity to auditory and painful stimulation, subsequently dichotomized as "reactive" vs. "non-reactive" [30, 80, 85]: the presence of a continuous and reactive EEG background (i.e. a change in EEG frequency and amplitude following stimulation) was associated with good prognosis. At this time TH is considered the standard of care after CA. Hypothermia and sedation used during cooling alter motor response and decrease the prognostic accuracy of neurological examination. Several studies performed in patients treated with $\mathrm{TH}$ demonstrated that EEG improves prognostic prediction of coma after CA [63, 86-95]. The presence of discontinuous and burst-suppression patterns, and of nonreactive EEG background, were strongly correlated (false-positive rates for poor prognosis $<10 \%$ ) with a poor prognosis, whilst a continuous reactive background was associated with good recovery. Importantly, in some studies, coma prognostication could be achieved during TH $[63,92,93]$.

\section{Recommendations for comatose patients after $C A$}

1. We recommend EEG during TH and within $24 \mathrm{~h}$ after rewarming to rule out $\mathrm{NCSz}$ in all comatose patients after CA (strong recommendation, low quality of evidence-grade $1 \mathrm{C}$ ).
2. We suggest EEG to assist with prognostication of coma after CA, particularly in patients treated with $\mathrm{TH}$ (weak recommendation, low quality of evidencegrade $2 \mathrm{C}$ ).

\section{EEG in patients with infectious and non-infectious encephalitis}

Seizure detection Central nervous system (CNS) infections, mainly acute meningitis/encephalitis, are a risk factor for seizures, ranging from 6-12\% in some studies [96], and seizures are associated with higher mortality rates [97]. In a small retrospective study, Carrera et al., found seizures in one-third of 42 patients with primary CNS infections, and the majority of these were NCSz [98]. In the large cohort of patients undergoing cEEG monitoring reported by the Columbia University group, CNS infections and metabolic encephalopathy accounted for $13 \%$ of all patients and there was $23 \%$ and $12 \%$ frequency of NCSE and NCSz, respectively. Comatose patients needed more than $24 \mathrm{~h}$ of cEEG monitoring to detect NCSz [17]. In another large cohort of neurocritical care patients $(n=393)$ with admission GCS $\leq 12$ and at least one EEG (cEEG, $n=34$ ), the prevalence of NCSz was $13 \%$ and was highest among those with CNS infection, together with anoxic encephalopathy [99]. $\mathrm{NCSz}$ are very frequent in noninfectious encephalitis (up to $78 \%$ of cases) and are mostly nonconvulsive [100].

Ischemia detection No study has provided data on ischemia detection in patients with encephalitis.

Prognostication No study has analyzed the prognostic accuracy of EEG in patients with encephalitis but particular patterns such as "delta brush" may be associated with a more prolonged illness [100].

\section{Recommendations for patients with infectious and non- infectious encephalitis}

1. We recommend EEG in patients with encephalitis that are comatose or have unexplained neurological deficits to rule out $\mathrm{NCSz}$ (strong recommendation, low quality of evidence-grade 1C).

2. We suggest EEG in patients with encephalitis to assist with prognosis (weak recommendation, very low quality of evidence-grade 2D).

\section{EEG in comatose ICU patients without acute primary brain injury}

Seizure detection In a retrospective cohort of 238 general ICU comatose patients in whom EEG was performed, Towne et al. found a prevalence of NCSz of $8 \%$ [29]. 
Postanoxic encephalopathy ( $42 \%$ ) was the most common etiology, followed by AIS ( $22 \%$ ), CNS infection, TBI, metabolic encephalopathy, alcohol or AED withdrawal (5\%), and brain tumor (all $5 \%$ ). Using standard 20-min EEG, Scozzafava found NCSz only in 2 of 169 patients with GCS $<8$ [101]. In 286 patients, of whom $22 \%$ had encephalitis and $24 \%$ metabolic encephalopathy, Firosh Khan et al. found that $4 \%$ had NCSE and $10 \% \mathrm{NCSz}$ [102]. Patients with primary brain injury had a higher incidence of NCSz than those with metabolic encephalopathy (32\% vs. $4 \%)$ [103]. Only two studies specifically focused on patients admitted to the ICU without a primary acute brain condition, in whom cEEG was performed because of altered consciousness. Young et al. found no NCSz among 62 patients with sepsis [104]. In a retrospective cohort of 201 medical ICU patients monitored with cEEG, Oddo et al. found a $10 \%$ frequency of seizures, of which $69 \%$ were purely NCSz [105]. Sepsis was the most common etiology and was the only independent risk factor for seizures. These findings confirm those of previous studies showing that septic encephalopathy and metabolic dysfunction (mainly renal and hepatic failure) are risk factors for NCSz [11, 106, 107].

Ischemia detection No study has provided data on ischemia detection in medical/surgical ICU populations.

Prognostication Patients with $\mathrm{NCSz}$ had the highest mortality rate in a large neuro-ICU population, although this finding was not significant after adjustment for confounding factors [99]. The same results were found in another study [101]. Firosh Khan et al. [102] found $42 \%$ and $21 \%$ of patients with NCSE and NCSz, respectively, had a poor outcome, but did not analyze the prognostic value of these findings. Young et al. [108] found that EEG suppression and lack of EEG reactivity were associated with a worse outcome in ICU patients; however, these data were only applicable to comatose CA patients. In a study of septic patients, the same group found that EEG abnormalities, but not NCSz, were associated with mortality $(0 \%$ in patients with normal EEG, $19 \%$ in patients with theta rhythm, $36 \%$ in patients with delta rhythm, $50 \%$ in patients with triphasic waves and $67 \%$ in patients with suppression) [104]. NCSz was associated with a poor outcome in septic patients [105] and in critically ill elderly ( $>65$ years of age) patients [109].

\section{Recommendations for comatose ICU patients without acute primary brain injury}

1. We suggest EEG in comatose ICU patients without an acute primary brain condition and with unexplained impairment of mental status or unexplained neurological deficits to rule out NCSz, particularly in those with severe sepsis or renal/hepatic failure (weak recommendation, low quality of evidence-grade 2C).

\section{Technological issues}

Duration of monitoring: continuous vs. intermittent EEG monitoring

Seizure detection Continuous EEG allows the detection of NCSz $[11,18,103,110]$ but there is controversy as to the minimum duration of cEEG. In a single-center retrospective study, about $50 \%$ of NCSz were detected within the first $60 \mathrm{~min}$ of EEG, but in comatose neuro-ICU patients at least $24 \mathrm{~h}$ and up to $48 \mathrm{~h}$ of monitoring may be required [17]. Continuous EEG is essential to titrate AED in RSE and to identify recurrent NCSz [15]. Intermittent ( $<30$ min duration) EEG may be insufficiently sensitive to detect NCSz [101], but no studies have compared continuous to intermittent EEG. Standard EEG can provide useful information in selected clinical situations, such as epilepsy-related situations, CA and brain death examination [102, 111]. In a recent study, independent predictors of epileptiform activity included a history of convulsive seizure(s), increasing age, deeper coma, and female gender [99]. In this study, the "number needed to monitor" was seven, i.e. at least seven neuro-ICU patients should undergo intermittent EEG to diagnose one with seizures.

Ischemia detection Continuous EEG using qEEG analysis has been used to detect cerebral ischemia in comatose SAH patients and in subjects with AIS. In SAH patients at risk of DCI, monitoring is performed for several days, during maximum DCI risk [37, 39, 41], and on average for 7 days [39]. QEEG is similarly performed for several days after AIS, one study reporting an average of $83 \mathrm{~h}$ of monitoring [47].

Prognostication After CA and TH, EEG-intermittent or continuous-improves coma prognostication [63, 86$95,112]$. Whether cEEG has higher prognostic accuracy than intermittent EEG has not been evaluated. Early prognostication of AIS [56-59], ICH [44, 46] and SAH [42] has exclusively been assessed with cEEG.

\section{Recommendations for continuous EEG over intermittent} EEG monitoring

1. We recommend cEEG for seizure detection in patients with RSE (strong recommendation, low quality of evidence-grade 1C).

2. We suggest cEEG for seizure detection in patients with SE that do not return to functional baseline within 60 min after administration of seizure medication 
(weak recommendation, low quality of evidencegrade 2C).

3. We suggest cEEG for seizure detection in comatose ICU patients (TBI, SAH, ICH, coma after CA, encephalitis, and septic and metabolic encephalopathy) with unexplained and persistent altered consciousness (weak recommendation, low quality of evidencegrade 2C).

4. We suggest cEEG for ischemia detection in comatose $\mathrm{SAH}$ patients in whom neurological examination is unreliable (weak recommendation, low quality of evidence-grade 2C).

5. We suggest cEEG to assist with prognostication of coma after CA (weak recommendation, low quality of evidence-grade $2 \mathrm{C}$ ).

\section{Montage: standard vs. simplified}

Seizure detection The placement of 21 electrodes is the standard method for EEG monitoring. Compared to standard EEG, the sensitivities of simplified EEG for seizure detection were $93 \%$ in one study using seven electrodes [113], $68 \%$ in another study using four electrodes [114], and $40 \%$ with single-channel EEG [115].
Ischemia detection All studies that examined the value of EEG for ischemia detection used a standard montage $[37,39,41,47]$.

Prognostication After CA and TH, EEG-intermittent or continuous-improves coma prognostication. The majority of the studies used a standard EEG montage [86, 88-92, 94, 95, 112], but others showed similar predictive values using simplified montages [63, 87, 93]. Prognostication of AIS [56-59], ICH [44, 46] and SAH [42] has exclusively been assessed with a standard montage.

\section{Recommendations for standard vs. simplified EEG montage in ICU patients}

1. We recommend a standard EEG montage (21 electrodes) for the detection of NCSz in ICU patients (weak recommendation, poor quality of evidencegrade $2 \mathrm{C}$ ).

Acknowledgments This report has been endorsed by the European Society of Intensive Care Medicine. Mauro Oddo is Deputy Chair of the Neurointensive Care section of the European Society of Intensive Care Medicine.

Conflicts of interest None.

\section{References}

1. Bratton SL, Chestnut RM, Ghajar J, McConnell Hammond FF, Harris OA, Hartl R, Manley GT, Nemecek A, Newell DW, Rosenthal G, Schouten J, Shutter L, Timmons SD, Ullman JS, Videtta W, Wilberger JE, Wright DW (2007) Guidelines for the management of severe traumatic brain injury. XI. Anesthetics, analgesics, and sedatives. J Neurotrauma 24(Suppl 1):S71-S76

2. Zamperetti N, Bellomo R, Defanti CA, Latronico N (2004) Irreversible apnoeic coma 35 years later. Towards a more rigorous definition of brain death? Intensive Care Med 30:1715-1722

3. Liberati A, Altman DG, Tetzlaff J, Mulrow C, Gotzsche PC, Ioannidis JP, Clarke M, Devereaux PJ, Kleijnen J, Moher D (2009) The PRISMA statement for reporting systematic reviews and meta-analyses of studies that evaluate healthcare interventions: explanation and elaboration. BMJ 339:b2700
4. Atkins D, Best D, Briss PA, Eccles M, Falck-Ytter Y, Flottorp S, Guyatt GH, Harbour RT, Haugh MC, Henry D, Hill S, Jaeschke R, Leng G, Liberati A, Magrini N, Mason J, Middleton P, Mrukowicz J, O'Connell D, Oxman AD, Phillips B, Schunemann HJ, Edejer TT, Varonen H, Vist GE, Williams JW Jr, Zaza S (2004) Grading quality of evidence and strength of recommendations. BMJ 328:1490

5. Schunemann HJ, Oxman AD, Brozek J, Glasziou P, Jaeschke R, Vist GE, Williams JW Jr, Kunz R, Craig J, Montori VM, Bossuyt P, Guyatt GH, Group GW (2008) Grading quality of evidence and strength of recommendations for diagnostic tests and strategies. BMJ 336:1106-1110

6. Brophy GM, Bell R, Claassen J, Alldredge B, Bleck TP, Glauser T, Laroche SM, Riviello JJ Jr, Shutter L, Sperling MR, Treiman DM, Vespa PM (2012) Guidelines for the evaluation and management of status epilepticus. Neurocrit Care 17:3-23
7. Reinhart K, Perner A, Sprung CL, Jaeschke R, Schortgen F, Johan Groeneveld AB, Beale R, Hartog CS (2012) Consensus statement of the ESICM task force on colloid volume therapy in critically ill patients. Intensive Care Med 38:368-383

8. DeLorenzo RJ, Waterhouse EJ, Towne AR, Boggs JG, Ko D, DeLorenzo GA, Brown A, Garnett L (1998) Persistent nonconvulsive status epilepticus after the control of convulsive status epilepticus. Epilepsia 39:833-840

9. Drislane FW (2000) Presentation, evaluation, and treatment of nonconvulsive status epilepticus. Epilepsy Behav 1:301-314

10. Privitera M, Hoffman M, Moore JL, Jester D (1994) EEG detection of nontonic-clonic status epilepticus in patients with altered consciousness. Epilepsy Res 18:155-166

11. Young B, Jordan K, Doig G (1996) An assessment of nonconvulsive seizures in the intensive care unit using continuous EEG monitoring: an investigation of variables associated with mortality. Neurology 47:83-89 
12. Claassen J, Hirsch LJ, Emerson RG, Mayer SA (2002) Treatment of refractory status epilepticus with pentobarbital, propofol, or midazolam: a systematic review. Epilepsia 43:146-153

13. Rossetti AO, Logroscino G, Bromfield EB (2005) Refractory status epilepticus: effect of treatment aggressiveness on prognosis. Arch Neurol 62:1698-1702

14. Rossetti AO, Milligan TA, Vulliemoz S, Michaelides C, Bertschi M, Lee JW (2011) A randomized trial for the treatment of refractory status epilepticus. Neurocrit Care 14:4-10

15. Claassen J, Hirsch LJ, Emerson RG, Bates JE, Thompson TB, Mayer SA (2001) Continuous EEG monitoring and midazolam infusion for refractory nonconvulsive status epilepticus. Neurology 57:1036-1042

16. Abend NS, Dlugos DJ, Hahn CD, Hirsch LJ, Herman ST (2010) Use of EEG monitoring and management of non-convulsive seizures in critically ill patients: a survey of neurologists. Neurocrit Care 12:382-389

17. Claassen J, Mayer SA, Kowalski RG, Emerson RG, Hirsch LJ (2004) Detection of electrographic seizures with continuous EEG monitoring in critically ill patients. Neurology 62:1743-1748

18. Pandian JD, Cascino GD, So EL, Manno E, Fulgham JR (2004) Digital video-electroencephalographic monitoring in the neurologicalneurosurgical intensive care unit: clinical features and outcome. Arch Neurol 61:1090-1094

19. Vespa PM, Nuwer MR, Nenov V, Ronne-Engstrom E, Hovda DA, Bergsneider M, Kelly DF, Martin NA, Becker DP (1999) Increased incidence and impact of nonconvulsive and convulsive seizures after traumatic brain injury as detected by continuous electroencephalographic monitoring. J Neurosurg 91:750-760

20. Krishnamurthy KB, Drislane FW (1999) Depth of EEG suppression and outcome in barbiturate anesthetic treatment for refractory status epilepticus. Epilepsia 40:759-762

21. Friedman D, Claassen J, Hirsch LJ (2009) Continuous electroencephalogram monitoring in the intensive care unit. Anesth Analg 109:506-523

22. Mirski MA, Varelas PN (2008) Seizures and status epilepticus in the critically ill. Crit Care Clin 24:115-147 (ix)
23. Ronne-Engstrom E, Winkler T (2006) Continuous EEG monitoring in patients with traumatic brain injury reveals a high incidence of epileptiform activity. Acta Neurol Scand 114:47-53

24. Olivecrona M, Zetterlund B, RodlingWahlstrom M, Naredi S, Koskinen LO (2009) Absence of electroencephalographic seizure activity in patients treated for head injury with an intracranial pressuretargeted therapy. J Neurosurg 110:300-305

25. Amantini A, Fossi S, Grippo A, Innocenti $\mathrm{P}$, Amadori A, Bucciardini L, Cossu C, Nardini C, Scarpelli S, Roma V, Pinto F (2009) Continuous EEG-SEP monitoring in severe brain injury. Neurophysiol Clin 39:85-93

26. Vespa PM, Miller C, McArthur D, Eliseo M, Etchepare M, Hirt D, Glenn TC, Martin N, Hovda D (2007) Nonconvulsive electrographic seizures after traumatic brain injury result in a delayed, prolonged increase in intracranial pressure and metabolic crisis. Crit Care Med 35:2830-2836

27. Vespa PM, McArthur DL, Xu Y, Eliseo M, Etchepare M, Dinov I, Alger J, Glenn TP, Hovda D (2010) Nonconvulsive seizures after traumatic brain injury are associated with hippocampal atrophy. Neurology 75:792-798

28. Temkin NR (2009) Preventing and treating posttraumatic seizures: the human experience. Epilepsia 50(Suppl 2):10-13

29. Towne AR, Waterhouse EJ, Boggs JG, Garnett LK, Brown AJ, Smith JR Jr, DeLorenzo RJ (2000) Prevalence of nonconvulsive status epilepticus in comatose patients. Neurology $54: 340-345$

30. Synek VM (1990) Revised EEG coma scale in diffuse acute head injuries in adults. Clin Exp Neurol 27:99-111

31. Gutling E, Gonser A, Imhof HG, Landis T (1995) EEG reactivity in the prognosis of severe head injury. Neurology 45:915-918

32. Steudel WI, Kruger J (1979) Using the spectral analysis of the EEG for prognosis of severe brain injuries in the first post-traumatic week. Acta Neurochir Suppl (Wien) 28:40-42

33. Vespa PM, Boscardin WJ, Hovda DA, McArthur DL, Nuwer MR, Martin NA, Nenov V, Glenn TC, Bergsneider M, Kelly DF, Becker DP (2002) Early and persistent impaired percent alpha variability on continuous electroencephalography monitoring as predictive of poor outcome after traumatic brain injury. J Neurosurg 97:84-92
34. Claassen J, Peery S, Kreiter KT, Hirsch LJ, Du EY, Connolly ES, Mayer SA (2003) Predictors and clinical impact of epilepsy after subarachnoid hemorrhage. Neurology 60:208-214

35. Dennis LJ, Claassen J, Hirsch LJ, Emerson RG, Connolly ES, Mayer SA (2002) Nonconvulsive status epilepticus after subarachnoid hemorrhage. Neurosurgery 51:1136-1143 (discussion 1144)

36. Little AS, Kerrigan JF, McDougall CG, Zabramski JM, Albuquerque FC, Nakaji P, Spetzler RF (2007) Nonconvulsive status epilepticus in patients suffering spontaneous subarachnoid hemorrhage. J Neurosurg 106:805-811

37. Claassen J, Hirsch LJ, Kreiter KT, Du EY, Connolly ES, Emerson RG, Mayer SA (2004) Quantitative continuous EEG for detecting delayed cerebral ischemia in patients with poor-grade subarachnoid hemorrhage. Clin Neurophysiol 115:2699-2710

38. Labar DR, Fisch BJ, Pedley TA, Fink ME, Solomon RA (1991) Quantitative EEG monitoring for patients with subarachnoid hemorrhage.

Electroencephalogr Clin Neurophysiol 78:325-332

39. Rathakrishnan R, Gotman J, Dubeau F, Angle M (2011) Using continuous electroencephalography in the management of delayed cerebral ischemia following subarachnoid hemorrhage. Neurocrit Care 14:152-161

40. Rivierez M, Landau-Ferey J, Grob R, Grosskopf D, Philippon J (1991) Value of electroencephalogram in prediction and diagnosis of vasospasm after intracranial aneurysm rupture. Acta Neurochir (Wien) 110:17-23

41. Vespa PM, Nuwer MR, Juhasz C, Alexander M, Nenov V, Martin N, Becker DP (1997) Early detection of vasospasm after acute subarachnoid hemorrhage using continuous EEG ICU monitoring. Electroencephalogr Clin Neurophysiol 103:607-615

42. Claassen J, Hirsch LJ, Frontera JA, Fernandez A, Schmidt M, Kapinos G, Wittman J, Connolly ES, Emerson RG, Mayer SA (2006) Prognostic significance of continuous EEG monitoring in patients with poor-grade subarachnoid hemorrhage. Neurocrit Care 4:103-112

43. Bosco E, Marton E, Feletti A, Scarpa B, Longatti P, Zanatta P, Giorgi E, Sorbara C (2011) Dynamic monitors of brain function: a new target in neurointensive care unit. Crit Care 15:R170 
44. Claassen J, Jette N, Chum F, Green R, Schmidt M, Choi H, Jirsch J, Frontera JA, Connolly ES, Emerson RG, Mayer SA, Hirsch LJ (2007) Electrographic seizures and periodic discharges after intracerebral hemorrhage. Neurology 69:1356-1365

45. Mecarelli O, Pro S, Randi F, Dispenza S, Correnti A, Pulitano P, Vanacore N, Vicenzini E, Toni D (2011) EEG patterns and epileptic seizures in acute phase stroke. Cerebrovasc Dis 31:191-198

46. Vespa PM, O'Phelan K, Shah M, Mirabelli J, Starkman S, Kidwell C, Saver J, Nuwer MR, Frazee JG, McArthur DA, Martin NA (2003) Acute seizures after intracerebral hemorrhage: a factor in progressive midline shift and outcome. Neurology 60:1441-1446

47. Diedler J, Sykora M, Bast T, Poli S, Veltkamp R, Mellado P, Steiner T, Rupp A (2009) Quantitative EEG correlates of low cerebral perfusion in severe stroke. Neurocrit Care 11:210-216

48. Huang Z, Dong W, Yan Y, Xiao Q, Man Y (2002) Effects of intravenous mannitol on EEG recordings in stroke patients. Clin Neurophysiol 113:446-453

49. Wood JH, Polyzoidis KS, Epstein CM, Gibby GL, Tindall GT (1984) Quantitative EEG alterations after isovolemic-hemodilutional augmentation of cerebral perfusion in stroke patients. Neurology 34:764-768

50. Diedler J, Sykora M, Juttler E, Veltkamp R, Steiner T, Rupp A (2010) EEG power spectrum to predict prognosis after hemicraniectomy for space-occupying middle cerebral artery infarction. Cerebrovasc Dis 29:162-169

51. Burghaus L, Hilker R, Dohmen C, Bosche B, Winhuisen L, Galldiks N, Szelies B, Heiss WD (2007) Early electroencephalography in acute ischemic stroke: prediction of a malignant course? Clin Neurol Neurosurg 109:45-49

52. Burghaus L, Liu WC, Dohmen C, Haupt WF, Fink GR, Eggers C (2012) Prognostic value of electroencephalography and evoked potentials in the early course of malignant middle cerebral artery infarction. Neurol Sci [Epub ahead of print]

53. Fernandez-Bouzas A, Harmony $T$, Fernandez T, Silva-Pereyra J, Valdes P, Bosch J, Aubert E, Casian G, Otero Ojeda G, Ricardo J, HernandezBallesteros A, Santiago E (2000) Sources of abnormal EEG activity in brain infarctions. Clin Electroencephalogr 31:165-169
54. Cillessen JP, van Huffelen AC, Kappelle LJ, Algra A, van Gijn J (1994) Electroencephalography improves the prediction of functional outcome in the acute stage of cerebral ischemia. Stroke 25:1968-1972

55. Hossmann KA, Heiss WD, Bewermeyer H, Mies G (1980) EEG frequency analysis in the course of acute ischemic stroke. Neurosurg Rev 3:31-36

56. Sheorajpanday RV, Nagels G, Weeren AJ, De Deyn PP (2011) Quantitative EEG in ischemic stroke: correlation with infarct volume and functional status in posterior circulation and lacunar syndromes. Clin Neurophysiol 122:884-890

57. Sheorajpanday RV, Nagels G, Weeren AJ, De Surgeloose D, De Deyn PP (2010) Additional value of quantitative EEG in acute anterior circulation syndrome of presumed ischemic origin. Clin Neurophysiol 121:1719-1725

58. Sheorajpanday RV, Nagels G, Weeren AJ, van Putten MJ, De Deyn PP (2011) Quantitative EEG in ischemic stroke: correlation with functional status after 6 months. Clin Neurophysiol 122:874-883

59. van Putten MJ, Tavy DL (2004) Continuous quantitative EEG monitoring in hemispheric stroke patients using the brain symmetry index. Stroke 35:2489-2492

60. Legriel S, Bruneel F, Sediri H, Hilly J, Abbosh N, Lagarrigue MH, Troche G, Guezennec P, Pico F, Bedos JP (2009) Early EEG monitoring for detecting postanoxic status epilepticus during therapeutic hypothermia: a pilot study. Neurocrit Care 11(3):338-344

61. Rittenberger JC, Popescu A, Brenner RP, Guyette FX, Callaway CW (2012) Frequency and timing of nonconvulsive status epilepticus in comatose post-cardiac arrest subjects treated with hypothermia. Neurocrit Care 16:114-122

62. Rossetti AO, Logroscino G, Liaudet L, Ruffieux C, Ribordy V, Schaller MD, Despland PA, Oddo M (2007) Status epilepticus: an independent outcome predictor after cerebral anoxia. Neurology 69:255-260

63. Rundgren M, Rosen I, Friberg H (2006) Amplitude-integrated EEG (aEEG) predicts outcome after cardiac arrest and induced hypothermia. Intensive Care Med 32:836-842

64. Rossetti AO, Oddo M, Liaudet L, Kaplan PW (2009) Predictors of awakening from postanoxic status epilepticus after therapeutic hypothermia. Neurology 72:744-749
65. Alving J, Moller M, Sindrup E, Nielsen BL (1979) 'Alpha pattern coma' following cerebral anoxia. Electroencephalogr Clin Neurophysiol 47:95-101

66. Bassetti C, Bomio F, Mathis J, Hess CW (1996) Early prognosis in coma after cardiac arrest: a prospective clinical, electrophysiological, and biochemical study of 60 patients. J Neurol Neurosurg Psychiatry 61:610-615

67. Berek K, Lechleitner P, Luef G, Felber S, Saltuari L, Schinnerl A, Traweger C, Dienstl F, Aichner F (1995) Early determination of neurological outcome after prehospital cardiopulmonary resuscitation. Stroke 26:543-549

68. Berkhoff M, Donati F, Bassetti C (2000) Postanoxic alpha (theta) coma: a reappraisal of its prognostic significance. Clin Neurophysiol 111:297-304

69. Binnie CD, Prior PF, Lloyd DS, Scott DF, Margerison JH (1970) Electroencephalographic prediction of fatal anoxic brain damage after resuscitation from cardiac arrest. $\mathrm{Br}$ Med J 4:265-268

70. Chen R, Bolton CF, Young B (1996) Prediction of outcome in patients with anoxic coma: a clinical and electrophysiologic study. Crit Care Med 24:672-678

71. Chokroverty S (1975) "Alpha-like" rhythms in electroencephalograms in coma after cardiac arrest. Neurology 25:655-663

72. Hockaday JM, Potts F, Epstein E, Bonazzi A, Schwab RS (1965) Electroencephalographic changes in acute cerebral anoxia from cardiac or respiratory arrest. Electroencephalogr Clin Neurophysiol 18:575-586

73. Lemmi H, Hubbert $\mathrm{CH}$, Faris AA (1973) The electroencephalogram after resuscitation of cardiocirculatory arrest. J Neurol Neurosurg Psychiatry 36:997-1002

74. Moller M, Holm B, Sindrup E, Nielsen BL (1978) Electroencephalographic prediction of anoxic brain damage after resuscitation from cardiac arrest in patients with acute myocardial infarction. Acta Med Scand 203:31-37

75. Morillo LE, Tulloch JW, Gumnit RJ, Snyder BD (1983) Compressed spectral array patterns following cardiopulmonary arrest. A preliminary report. Arch Neurol 40:287-289

76. Rothstein TL, Thomas EM, Sumi SM (1991) Predicting outcome in hypoxicischemic coma. A prospective clinical and electrophysiologic study. Electroencephalogr Clin Neurophysiol 79:101-107 
77. Sandroni C, Barelli A, Piazza O, Proietti R, Mastria D, Boninsegna R (1995) What is the best test to predict outcome after prolonged cardiac arrest? Eur J Emerg Med 2:33-37

78. Scollo-Lavizzari G, Bassetti C (1987) Prognostic value of EEG in postanoxic coma after cardiac arrest. Eur Neurol 26:161-170

79. Sorensen K, Thomassen A, Wernberg M (1978) Prognostic significance of alpha frequency EEG rhythm in coma after cardiac arrest. J Neurol Neurosurg Psychiatry 41:840-842

80. Synek VM (1989) Validity of a revised EEG coma scale for predicting survival in anoxic encephalopathy. Clin Exp Neurol 26:119-127

81. Synek VM, Shaw NA (1989) Epileptiform discharges in presence of continuous background activity in anoxic coma. Clin Electroencephalogr 20:141-146

82. Yamashita S, Morinaga T, Ohgo S, Sakamoto T, Kaku N, Sugimoto S, Matsukura S (1995) Prognostic value of electroencephalogram (EEG) in anoxic encephalopathy after cardiopulmonary resuscitation: relationship among anoxic period, EEG grading and outcome. Intern Med 34:71-76

83. Young GB, Doig G, Ragazzoni A (2005) Anoxic-ischemic encephalopathy: clinical and electrophysiological associations with outcome. Neurocrit Care 2:159-164

84. Zandbergen EG, Hijdra A, Koelman JH, Hart AA, Vos PE, Verbeek MM, de Haan RJ (2006) Prediction of poor outcome within the first 3 days of postanoxic coma. Neurology 66:62-68

85. Synek VM (1990) Value of a revised EEG coma scale for prognosis after cerebral anoxia and diffuse head injury. Clin Electroencephalogr 21:25-30

86. Cloostermans MC, van Meulen FB, Eertman CJ, Hom HW, van Putten MJ (2012) Continuous

electroencephalography monitoring for early prediction of neurological outcome in postanoxic patients after cardiac arrest: a prospective cohort study. Crit Care Med 40:2867-2875

87. Cronberg T, Rundgren M, Westhall E, Englund E, Siemund R, Rosen I, Widner H, Friberg H (2011) Neuronspecific enolase correlates with other prognostic markers after cardiac arrest. Neurology 77:623-630
88. Daubin C, Guillotin D, Etard O, Gaillard C, du Cheyron D, Ramakers M, Bouchet B, Parienti JJ, Charbonneau P (2008) A clinical and EEG scoring system that predicts early cortical response (N20) to somatosensory evoked potentials and outcome after cardiac arrest. BMC Cardiovasc Disord 8:35

89. Fugate JE, Wijdicks EF, Mandrekar J, Claassen DO, Manno EM, White RD, Bell MR, Rabinstein AA (2010) Predictors of neurologic outcome in hypothermia after cardiac arrest. Ann Neurol 68:907-914

90. Kawai M, Thapalia U, Verma A (2011) Outcome from therapeutic hypothermia and EEG. J Clin Neurophysiol 28:483-488

91. Rossetti AO, Oddo M, Logroscino G, Kaplan PW (2010) Prognostication after cardiac arrest and hypothermia: a prospective study. Ann Neurol 67:301-307

92. Rossetti AO, Urbano LA, Delodder F, Kaplan PW, Oddo M (2010) Prognostic value of continuous EEG monitoring during therapeutic hypothermia after cardiac arrest. Crit Care 14:R173

93. Rundgren M, Westhall E, Cronberg T, Rosen I, Friberg H (2010) Continuous amplitude-integrated electroencephalogram predicts outcome in hypothermia-treated cardiac arrest patients. Crit Care Med 38:1838-1844

94. Tiainen M, Poutiainen E, Kovala T, Takkunen O, Happola O, Roine RO (2007) Cognitive and neurophysiological outcome of cardiac arrest survivors treated with therapeutic hypothermia. Stroke 38:2303-2308

95. Wennervirta JE, Ermes MJ, Tiainen SM, Salmi TK, Hynninen MS, Sarkela MO, Hynynen MJ, Stenman UH, Viertio-Oja HE, Saastamoinen KP, Pettila VY, Vakkuri AP (2009) Hypothermia-treated cardiac arrest patients with good neurological outcome differ early in quantitative variables of EEG suppression and epileptiform activity. Crit Care Med 37:2427-2435

96. Flores-Cordero JM, Amaya-Villar R, Rincon-Ferrari MD, Leal-Noval SR, Garnacho-Montero J, LlanosRodriguez AC, Murillo-Cabezas F (2003) Acute community-acquired bacterial meningitis in adults admitted to the intensive care unit: clinical manifestations, management and prognostic factors. Intensive Care Med 29:1967-1973
97. Zoons E, Weisfelt M, de Gans J, Spanjaard L, Koelman JH, Reitsma JB, van de Beek D (2008) Seizures in adults with bacterial meningitis. Neurology 70:2109-2115

98. Carrera E, Claassen J, Oddo M, Emerson RG, Mayer SA, Hirsch LJ (2008) Continuous electroencephalographic monitoring in critically ill patients with central nervous system infections. Arch Neurol 65:1612-1618

99. Kramer AH, Jette N, Pillay N, Federico P, Zygun DA (2012) Epileptiform activity in neurocritical care patients. Can J Neurol Sci 39:328-337

100. Schmitt SE, Pargeon K, Frechette ES, Hirsch LJ, Dalmau J, Friedman D (2012) Extreme delta brush: a unique EEG pattern in adults with antiNMDA receptor encephalitis. Neurology 79:1094-1100

101. Scozzafava J, Hussain MS, Brindley PG, Jacka MJ, Gross DW (2010) The role of the standard 20 min EEG recording in the comatose patient. J Clin Neurosci 17:64-68

102. Firosh Khan S, Ashalatha R, Thomas SV, Sarma PS (2005) Emergent EEG is helpful in neurology critical care practice. Clin Neurophysiol 116:2454-2459

103. Young GB, Doig GS (2005) Continuous EEG monitoring in comatose intensive care patients: epileptiform activity in etiologically distinct groups. Neurocrit Care 2:5-10

104. Young GB, Bolton CF, Archibald YM, Austin TW, Wells GA (1992) The electroencephalogram in sepsisassociated encephalopathy. J Clin Neurophysiol 9:145-152

105. Oddo M, Carrera E, Claassen J, Mayer SA, Hirsch LJ (2009) Continuous electroencephalography in the medical intensive care unit. Crit Care Med 37:2051-2056

106. Bergen DC, Ristanovic R, Gorelick PB, Kathpalia S (1994) Seizures and renal failures. Int J Artif Organs 17:247-251

107. Delanty N, Vaughan CJ, French JA (1998) Medical causes of seizures. Lancet 352:383-390

108. Young GB, Kreeft JH, McLachlan RS, Demelo J (1999) EEG and clinical associations with mortality in comatose patients in a general intensive care unit. J Clin Neurophysiol 16:354-360

109. Litt B, Wityk RJ, Hertz SH, Mullen PD, Weiss H, Ryan DD, Henry TR (1998) Nonconvulsive status epilepticus in the critically ill elderly. Epilepsia 39:1194-1202 
110. Sutter R, Fuhr P, Grize L, Marsch S, Ruegg S (2011) Continuous videoEEG monitoring increases detection rate of nonconvulsive status epilepticus in the ICU. Epilepsia 52:453-457

111. Varelas PN, Hacein-Bey L, Hether T, Terranova B, Spanaki MV (2004) Emergent electroencephalogram in the intensive care unit: indications and diagnostic yield. Clin EEG Neurosci 35:173-180
112. Rossetti AO, Carrera E, Oddo M (2012) Early EEG correlates of neuronal injury after brain anoxia. Neurology 78:796-802

113. Karakis I, Montouris GD, Otis JA, Douglass LM, Jonas R, Velez-Ruiz N, Wilford K, Espinosa PS (2010) A quick and reliable EEG montage for the detection of seizures in the critical care setting. J Clin Neurophysiol 27:100-105

114. Young GB, Sharpe MD, Savard M, Al Thenayan E, Norton L, DaviesSchinkel C (2009) Seizure detection with a commercially available bedside EEG monitor and the subhairline montage. Neurocrit Care 11:411-416
115. Nitzschke R, Muller J, Engelhardt R, Schmidt GN (2011) Single-channel amplitude integrated EEG recording for the identification of epileptic seizures by nonexpert physicians in the adult acute care setting. J Clin Monit Comput 25:329-337 